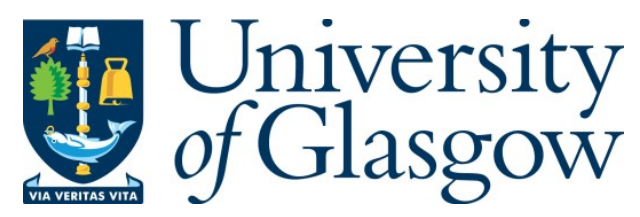

Walker, J.S., Green, R.B., Gillies, E.A. and Phillips, C. (2020) The effect of a barnacleshaped excrescence on the hydrodynamic performance of a tidal turbine blade section. Ocean Engineering, 217, 107849.

(doi: 10.1016/j.oceaneng.2020.107849)

This is the Author Accepted Manuscript.

There may be differences between this version and the published version. You are advised to consult the publisher's version if you wish to cite from it.

https://eprints.gla.ac.uk/221315/

Deposited on: 24 July 2020

Enlighten - Research publications by members of the University of Glasgow http://eprints.gla.ac.uk 


\title{
The effect of a barnacle-shaped excrescence on the hydrodynamic performance of a tidal turbine blade section
}

\author{
J. S. Walker ${ }^{1,2}$, R.B Green*1, E.A. Gillies ${ }^{1,3}$, and C. Phillips ${ }^{4}$ \\ ${ }^{1}$ Aerospace Science Division, University Of Glasgow, Glasgow, UK \\ ${ }^{2}$ Offshore Renewable Energy Catapult, Glasgow, UK \\ ${ }^{3}$ cbec eco-engineering UK Ltd, Inverness, UK \\ ${ }^{4}$ Andritz HydroHammerfest, Glasgow, UK
}

*richard.green@glasgow.ac.uk 


\begin{abstract}
Efficient tidal turbine designs rely upon the hydrodynamic performance of the turbine blade sections. A significant consideration for the likely power generation capacity of a tidal turbine is the effect of biofouling on the blade performance. A turbine blade surface is susceptible to large scale macrofouling, mainly from encrusters, such as barnacles and molluscs, colonising the developing surface. This paper considers the case of when a barnacle attaches to the upper (suction) surface of the blade section. Results of experiments to investigate the unsteady flow characteristics of the blade section are presented, and the modification of the hydrodynamic performance coefficients due to the presence of a barnacle is evaluated. The barnacle has no significant effect upon the lift in steady flow and unsteady flow, but there is a very large increase in the drag. Dependent upon the degree of barnacle encrustation, the effect on a turbine blade drag may be significant and lead to a degradation of a turbine predicted performance.
\end{abstract}

\title{
Keywords
}

Tidal turbine; biofouling; dynamic stall 


\section{NOMENCLATURE}

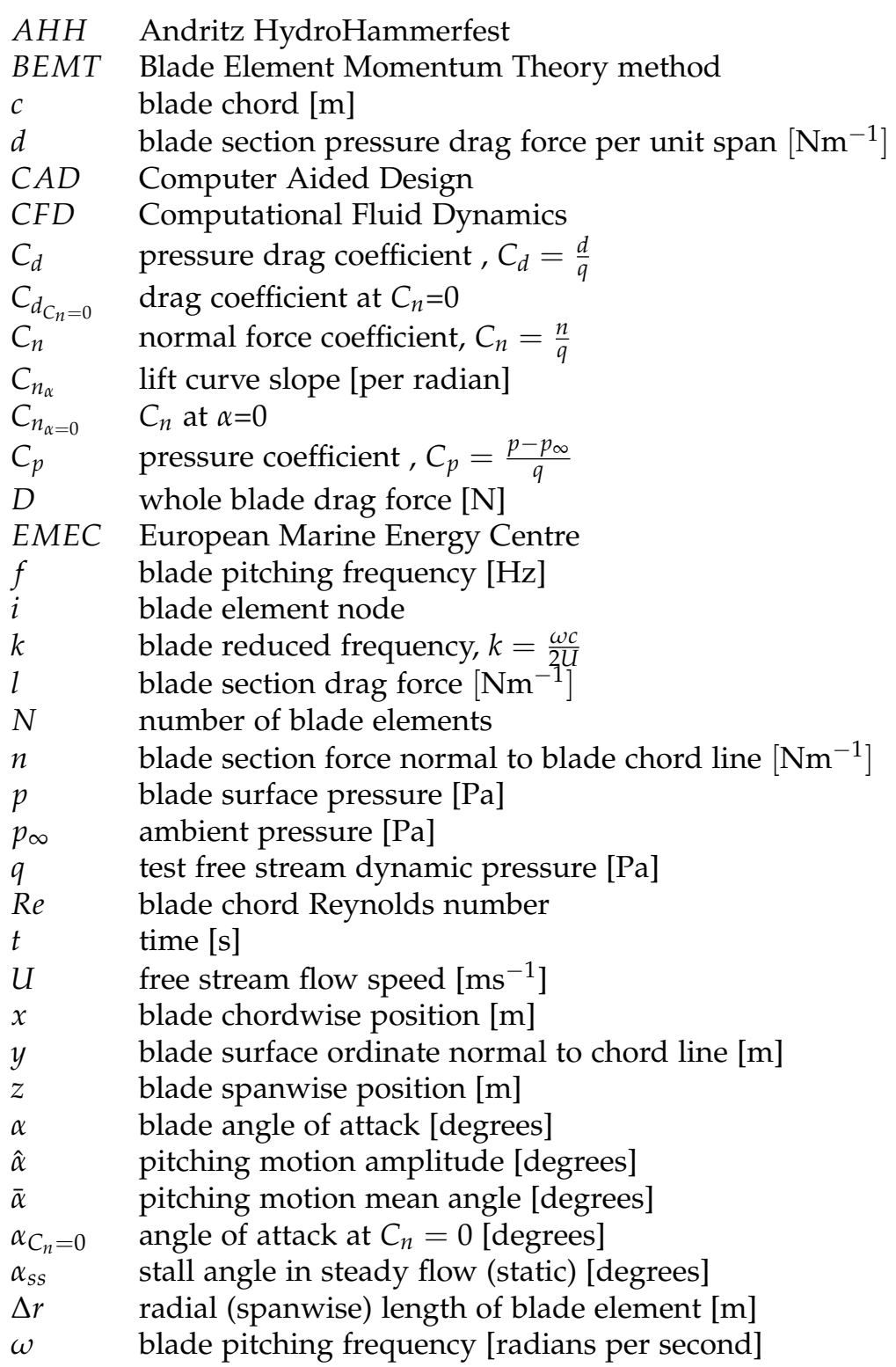




\section{Introduction}

The two-dimensional behaviour of aerofoil sections comprising turbine blades is critical to the baseline performance of the turbine, and the boundary layer behaviour is a critical factor. Tidal turbines operate in a challenging environment as far as the fluid dynamics are concerned; the flow is unsteady due to the turbine rotation, there is turbulence in the incident flow, and the marine environment leads to biofouling on the blade surface. Marine biofouling is defined as the unwanted accumulation of biological material on submerged man-made surfaces. The development of the biofouled surface can be described as the layering of increasingly larger scale fouling organisms that starts with the formation of a biofilm by microfouling agents (bacteria, diatoms, algae), and this is followed by progressively larger scale organisms, MartínRodríguez et al. (2015). Barnacle cluster formation is surface macrofouling by large-scale surface roughness. Even surfaces coated with anti-fouling coatings are susceptible, given time and/or any damage, and Vance et al. (2014) point out that anti-fouling coatings only delay, not prevent, biofilm formation. Surface roughness on an aerofoil, or flat plate, is known to result in premature boundary layer transition (Kerho and Bragg, 1997). In the case of isolated three-dimensional roughness elements, transition in the element wake can be predicted by correlations using the roughness-based critical Reynolds number (Tani, 1969). For roughness-based Reynolds numbers greater than the critical value, transition would be expected just downstream of the element, and the unsteady disturbance growth rate increases with increasing roughness-based Reynolds number (Ergin and White, 2006). Two approaches to the research are usually followed: investigations into the role of the roughness size and location on the transition location and performance (Roberts and Yaras, 2005); and investigations into the underlying hydrodynamic mechanisms which result in premature transition (Klebanoff et al., 1992). The majority of research into the hydrodynamic mechanisms has been limited to flat plates with zero pressure gradient and roughness heights smaller than the laminar boundary layer thickness.

Jacobs (1934) investigated larger scale protuberances, up to $0.0125 c$ height, at different chordwise locations on a NACA 0012 aerofoil, with negligible change in lift for lower surface protuberances, but large drag increases, particularly for roughness height greater than $0.005 c$ in the forward portion of the upper surface. Other work on aerofoil performance has included: leading edge ice accretion (Bragg et al., 2005; Cummings and Bragg, 1996); surface imperfections on gas turbine blades (Roberts and Yaras, 2005); and bio-inspired leading edge designs (Johari et al., 2007).

Barnacle fouling is not limited to the leading edge region of the blade, has a considerably larger roughness height of approximately $0.02 c$, and will be in a turbulent, not laminar, boundary layer on the tidal turbine blade. Despite significantly influencing the hydrodynamic loading of submerged offshore support structures (Theophanatos and Wolfram, 1989) and the efficiency and cost of maritime operations (Schultz et al., 2011), and now the performance of tidal turbines (Orme et al., 2001), the effect of barnacle fouling has not been widely reported in the available literature. Furthermore, the published data have focussed on static loading and not the dynamic loading a tidal turbine blade experiences, yet understanding biofouling, from both an engineering and ecological perspective, has been identified as a key operability challenge to advance the current technology (Mueller and Wallace, 2008; Ng et al., 2013). Investigations have primarily been concerned with quantifying the barnacle fouling effect based on lift and drag measurements, including that of Theophanatos and Wolfram (1989) which suggests that even the lightest of marine fouling may cause a substantial increase in drag. However, they conclude that an increase in hydrodynamic drag with surface cover is non-linear and depends primarily on the distribution of the roughness elements. In terms of a tidal turbine, Orme et al. (2001) studied the effects of barnacle fouling on a NACA 4424 aerofoil in a wind tunnel experiment, at a Reynolds number of $4 \times 10^{5}$. Arrays of conical extrusions, of different size and density, were applied to the model to represent the fouling, which was informed by a sample collection at a local marine site. The values for roughness element height ranged from $0.0035 c$ to $0.0285 c$. As expected, the performance of the aerofoil decreased as fouling variables increased, with a reduction in efficiency of $25 \%$ for low level fouling increasing to $70 \%$ at higher levels. The trend in drag increase was not seen in the lift coefficient which initially decreased with the introduction of fouling, but showed little 
variation with increasing fouling severity. In addition, the stall angle was observed to be delayed by approximately $10^{\circ}$. This paper remains the major reference on the subject over fifteen years on from its publication, but does not provide any understanding of the flow behaviour.

More recently, CFD has been utilised to investigate the systematic changes in the flow structure and underlying flow mechanisms - not just the effect on the aerofoil loading. Khor and Xiao (2011) used the work of Orme et al. (2001) as the basis for a numerical simulation, using a standard $\kappa-\epsilon$ model, of the fouling effects on the NACA 4424 aerofoil, and were generally in good agreement with the previous work. Alongside a lift-to-drag ratio reduction of up to $80 \%$, it was identified that with an increase in fouling, the stagnation moves forwards towards the leading edge and the area towards the trailing edge experiences significant separation, while areas of favourable pressure gradients decrease resulting in earlier separation, lower lift and stalled flow. However, both these investigations only considered widely distributed barnacle fouling and did not include the likely blade microfouling. Therefore, behaviour attributed to the barnacle may not be strictly correct.

Previous investigations (Orme et al., 2001; Khor and Xiao, 2011) into barnacle fouling have assumed evenly distributed fouling over both aerofoil surfaces, including the upper surface leading edge. However, this is in contrast to evidence available. Although difficult to measure experimentally, it is thought that the shear forces acting on the blade surface prevent barnacles from attaching on the upper surface of the blade towards the leading edge. It is only at chordwise location aft of the adverse pressure gradient, where the local shear stress at the wall decreases, and in separated flow where the shear stress is low enough for the barnacle to attach.This is supported by evidence of barnacle fouling distribution on a deployed tidal turbine blade, as shown in Figure 1, with the upper surface barnacle fouling falling into two distinct zones where no fouling is identified over the forward portion of the blade, but is located over the aft $40 \%$ of the blade. The image on the left of Figure 1 was taken during the recovery of the AHH HS1000 demonstrator device from its test berth at EMEC, and the drawing on the right highlights the location and distribution of barnacle fouling on the blade, and includes identified barnacles and calcareous membranes, where the barnacle has been dislodged. The assumption of the $60 \%$ chord barnacle fouling limit is clearly identified and marked on the diagram. The pictured device was deployed at EMEC during December 2011 and was recovered in early 2015 on completion of the test programme (EMEC, 2017).

Barnacle cluster formation has been a problem for shipping for centuries, and is worthy of mentioning in this introduction. It is a serious matter for hull resistance, see for example Demirel et al. (2017). In this study barnacle clusters of various size and density were fitted onto a flat plate model, that was towed along a water tank. When extrapolated to a typical full-sized vessel, friction coefficient and effective power increases of up to $100 \%$ and $66 \%$ were calculated for certain levels of barnacle coverage. CFD predictions of barnacle fouling on a ship and propeller were performed by Song et al. (2020a), and they reported increased propeller rotational speed at the self-propulsion point for both the fouled hull and the fouled propeller, and increases in shaft power for fouled hull and propeller of around $80 \%$ in the worst case. Song et al. (2019) and Song et al. (2020b) extended the CFD method used for ship hulls to do calculations on the effect of barnacle fouling on the performance of tidal turbines. Effects of different barnacle sizes and surface coverage were investigated, and significantly reduced power coefficients and changes to optimal operating conditions were observed.

The work in this paper describes a series of dynamic wind tunnel tests of an aerofoil model of a tidal turbine blade section fitted with a model of a barnacle to simulate the macrofouling. The tidal turbine section is a contemporary design intended to operate around the $75 \%$ radially outboard thrust producing location. The effects of the barnacle on the steady and unsteady hydrodynamic performance of the blade are discussed. Although the roughnessbased Reynolds number is approximately two orders greater than the critical value, in this work the barnacle is downstream of the aerofoil transition, therefore would not be expected to play a role in the transition process and quantifying the loading performance is the main objective. Unsteady tests used sinusoidal pitching motion profiles over a range of pitching frequencies, mean angles and pitch amplitudes, and test cases ranged from conditions expected to be typical of those encountered by an operational tidal turbine, and more extreme limiting cases. 


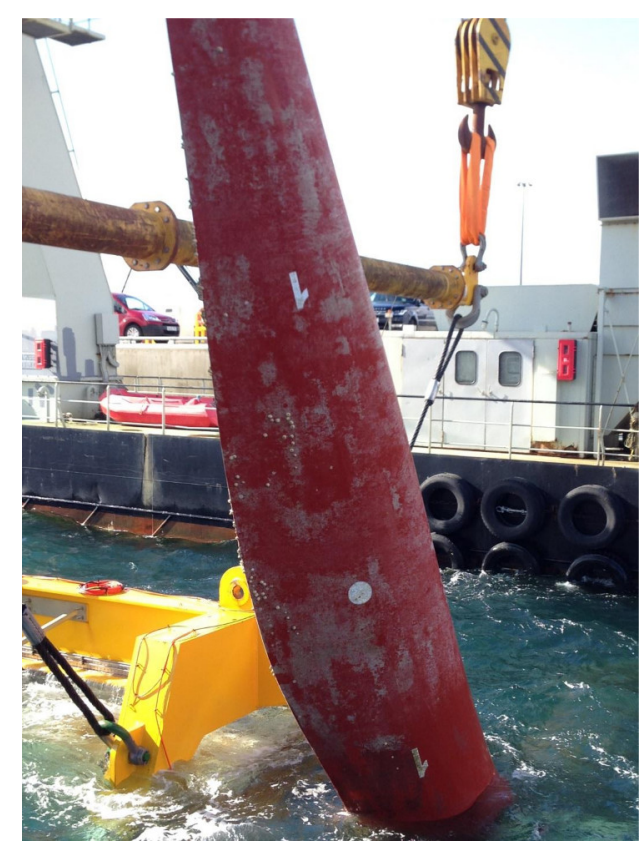

(A) AHH HS1000 Turbine at EMEC

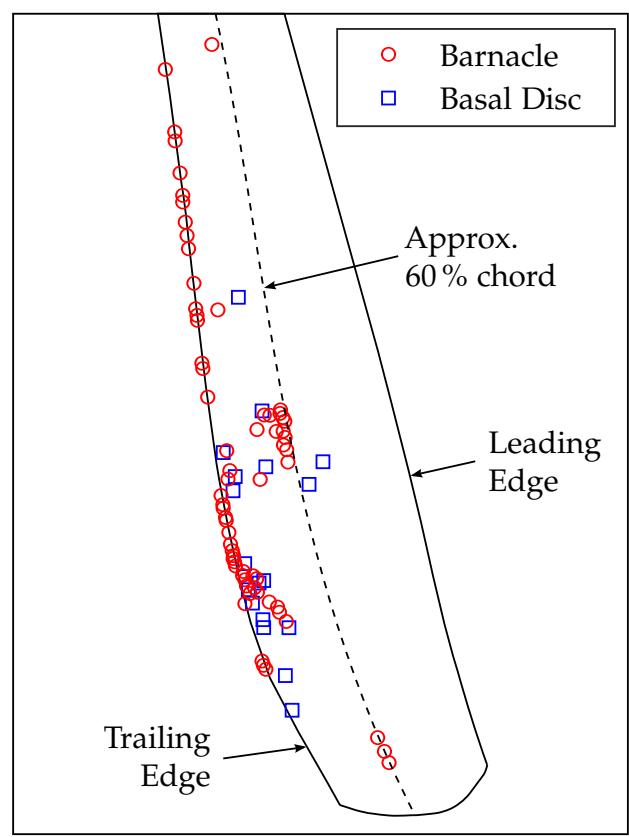

(в) Identified Barnacle Fouling Locations

FIGURE 1: Barnacle biofouling on a deployed tidal turbine blade, the mean blade chord is approximately $1 \mathrm{~m}$. Image supplied by AHH.

The change in the aerofoil section performance and a discussion of the three-dimensional aspects of the flow around the barnacle are provided.

\section{Experimental method}

Experimental tests at a blade chord Reynolds number $R e=1.5 \times 10^{6}$ were performed in the Handley-Page wind tunnel at the University of Glasgow. This is a closed-return wind tunnel with a $1.61 \mathrm{~m}$ high $\times 2.13 \mathrm{~m}$ wide $\times 2.74 \mathrm{~m}$ long working section and a $4: 1$ contraction ratio. The turbulence level at the operating wind tunnel speed of $45 \mathrm{~ms}^{-1}$ is $2.5 \%$. The wind tunnel is fitted with a dynamic model motion system specifically designed for experimental investigation of the unsteady aerodynamics of aerofoil sections and dynamic stall. This facility has been operational since the 1980s. Historically tests have measured the time evolution of the developing surface pressure distribution during the dynamic test, as this allows computation of the important aerodynamic coefficients and insight into the physical processes to be gained. The same approach was used in this set of tests. An extensive database of unsteady pressure data is available at http:/ / dx.doi.org/10.5525/gla.researchdata.464 Figure 3 shows a sketch of the dynamic stall test apparatus. Aerofoil models are pitched about the quarter-chord location by a hydraulically operated linear actuator and crank mechanism. This pitch axis location is realistic for the pitch axis of a turbine blade. An angular displacement transducer geared to the quarter-chord location provides angular position feedback to a PID controller driving the hydraulic actuator through a servo-valve, and the desired pitching waveform is fed to the PID controller by a D-TACQ Solutions ACQ1001Q waveform generator. The system is capable of providing pitching motions with peak-to-peak amplitudes up to 60 degrees at pitching frequencies up to $4 \mathrm{~Hz}$. A typical model motion profile was programmed as a sine wave with specified mean angle, amplitude and frequency, such that $\alpha(t)=\bar{\alpha}+\hat{\alpha} \sin \omega t$.

The blade section tested is the proprietary AHH19 section, which is an $18.8 \%$ thick blade section designed for use at the $75 \%$ radially outboard location of a tidal turbine. The section shape is similar to the NACA 63-619, and it is shown in figure 2. The blade section for the wind tunnel tests was manufactured with $c=0.55 \mathrm{~m}$ chord length, and spanned the full height of the wind tunnel. A array of 36 surface mounted pressure transducers was fitted around 


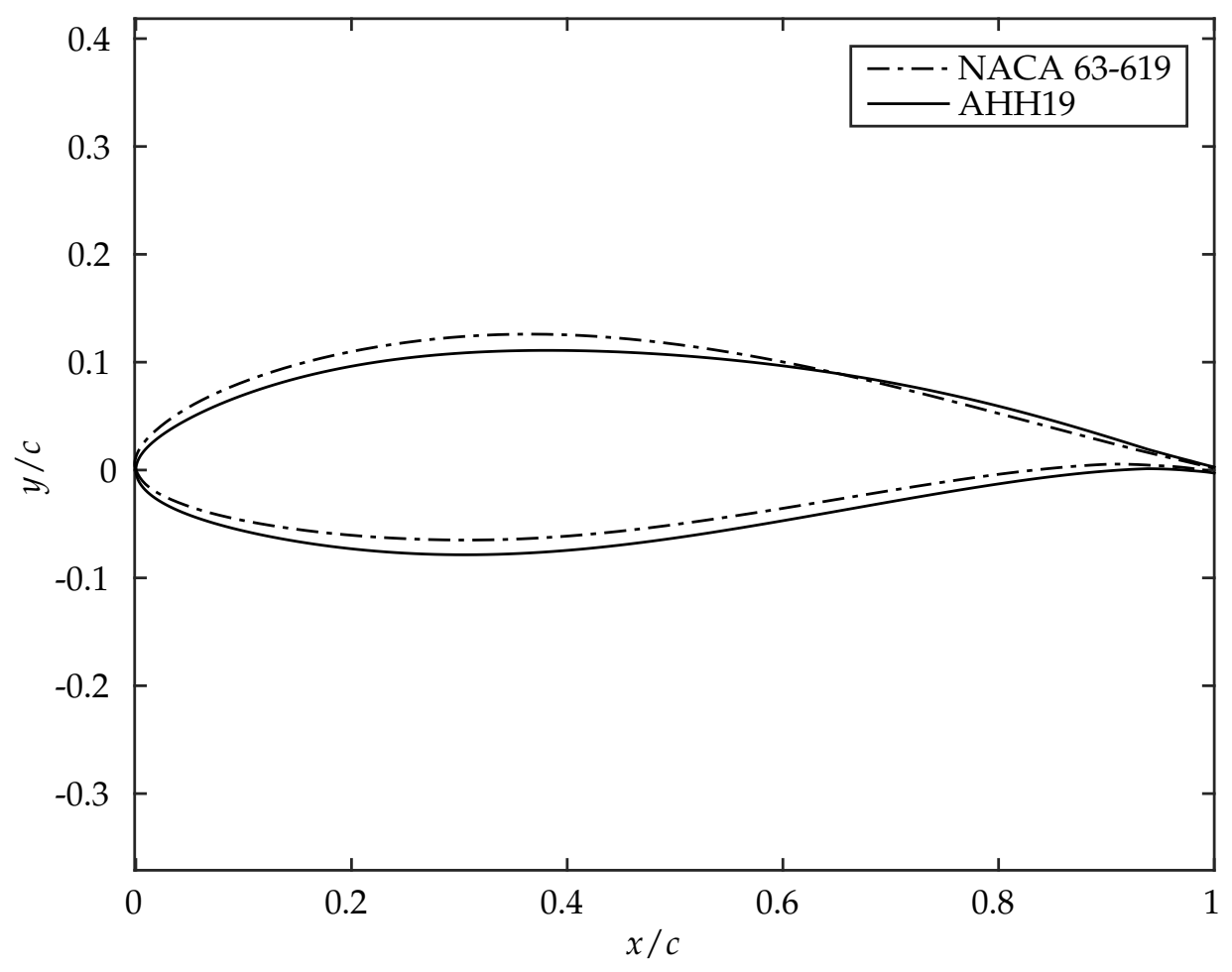

FIGURE 2: AHH19 aerofoil shape and comparison with NACA63-619

the mid-span of the model. First Sensor HDI series gauge sensors were selected; they can respond at $1 \mathrm{kHz}$, and therefore have sufficient bandwidth for the dynamic stall tests. Pressure data were sampled in parallel using a 96 channel D-TACQ Solutions ACQ2006 analogue to digital converter. Pressure transducer data were acquired simultaneously at a rate of $10 \mathrm{kHz}$ per channel at 24 bit resolution.

To represent the macro-fouled case, an instrumented barnacle model was manufactured and attached to the AHH 19 model. The barnacle was positioned on the aerofoil upper surface at $60 \%$ chord and $25 \%$ span ( $400 \mathrm{~mm}$ from the tunnel floor), so as not to influence the main aerofoil pressure measurements at midspan.

Literature widely reports basal diameters of different species (Southward, 2008), but due to many influencing factors and ecological variation the height is rarely reported. Vance et al. (2014), as part of the ETI ReDAPT project, identified the acorn barnacle Chirona hameri as the dominant fouling species at the EMEC Walls of Warness tidal site, with a basal diameter of over $25 \mathrm{~mm}$ and in some cases reaching heights of $30 \mathrm{~mm}$ to $40 \mathrm{~mm}$. Also in the fouling community were the smaller Balanus crenatus and Semibalanus balanoides species, which grow to diameters of $25 \mathrm{~mm}$ and $15 \mathrm{~mm}$ respectively. Barnes and Powell (1953) measured the length to height ratio of subtidal Balanus crenatus collected in the Firth of Clyde over a two year period, with a mean ratio of 2.9 for a $20 \mathrm{~mm}$ length. The widely referenced work of Orme et al. (2001) investigates a selection of barnacle sizes ranging from $0.0035 c$ to $0.0285 c$ for the roughness element height. A barnacle height of $0.02 c$ was selected for this investigation.

Although the barnacle species on the AHH turbine blade (See Figure 4) was not confirmed, all observed specimens were a similar size with a measured diameter of approximately $25 \mathrm{~mm}$. The barnacle model was based on a frustum (Sadique et al., 2015) with radii of $20 \mathrm{~mm}$ and $10 \mathrm{~mm}(0.036 \mathrm{c}$ and $0.018 c)$ and height $11 \mathrm{~mm}(0.02 c)$, as shown in Figure 5, and included nine pressure orifices around the outer faces. A further sixteen orifices were included around the 


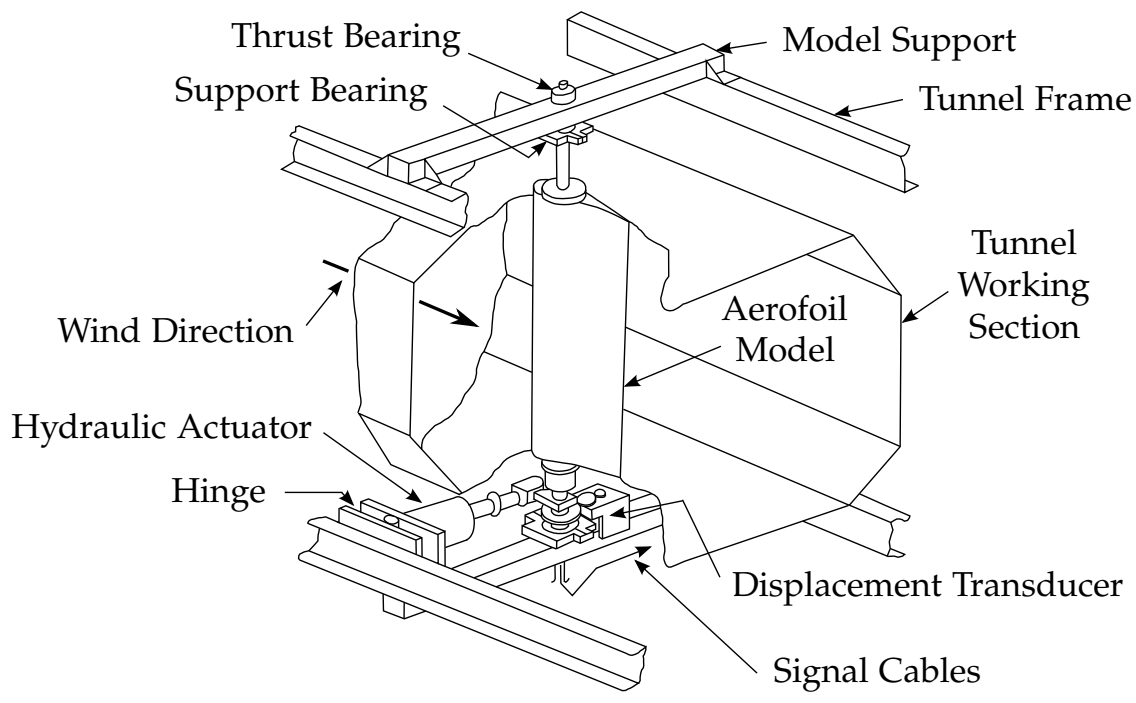

FIGURE 3: General arrangement of the dynamic stall test rig in the Handley-Page wind tunnel

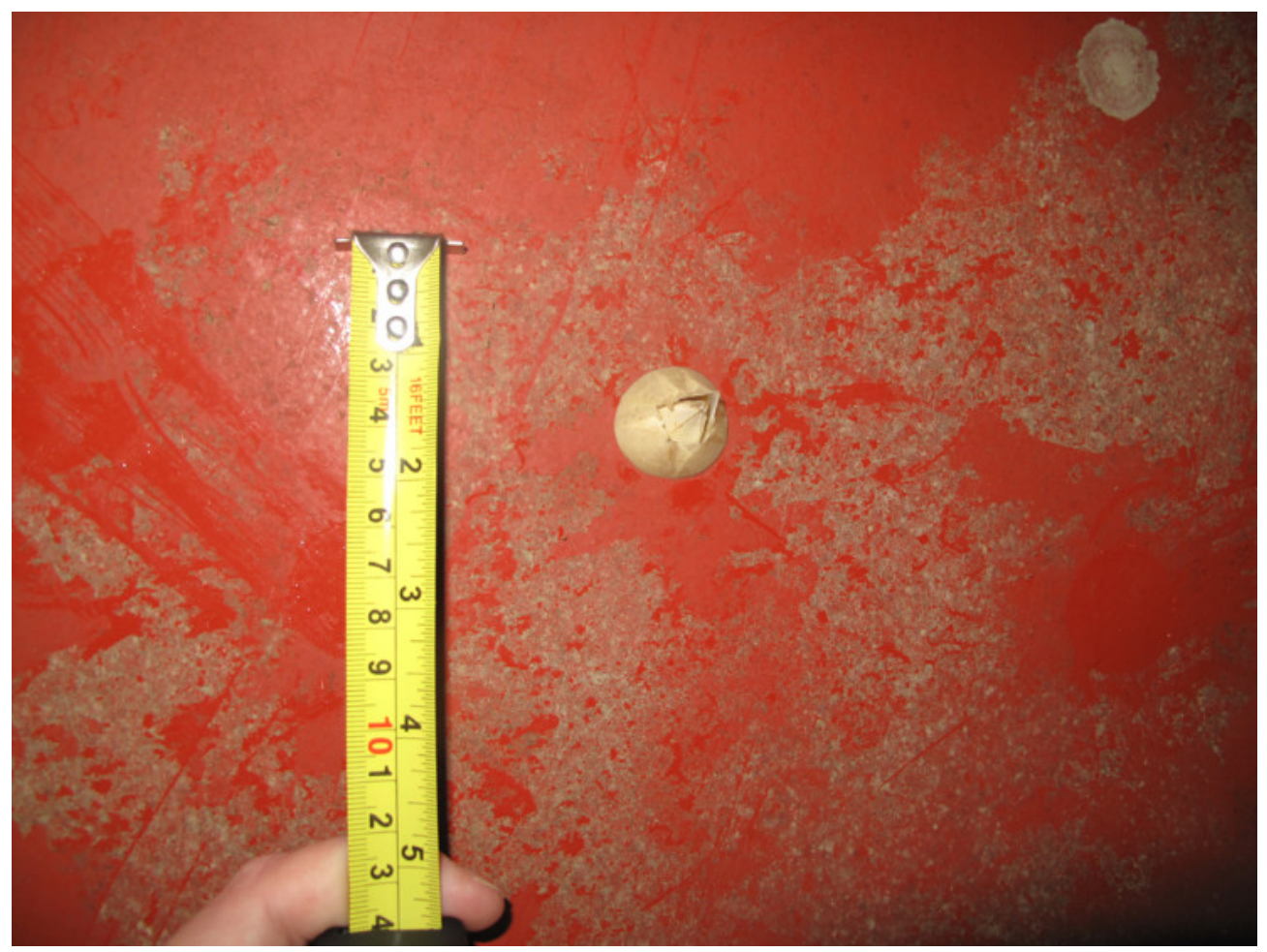

FiguRE 4: Barnacle biofouling on a deployed turbine blade showing a single, isolated barnacle. Image supplied by $\mathrm{AHH}$. 


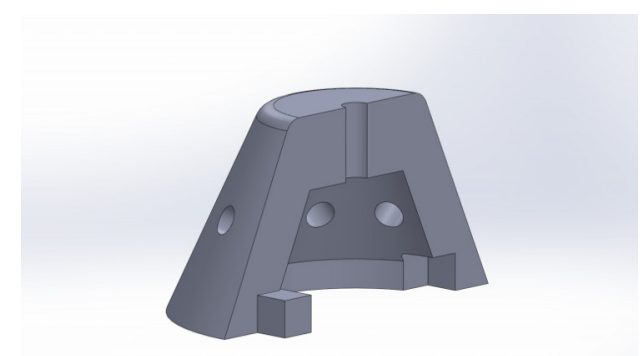

(A) CAD part view of barnacle model.

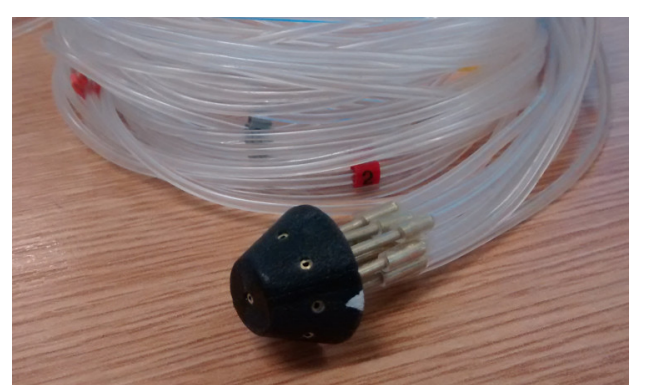

(в) Assembly of barnacle model prior to installation on blade model surface.

FIGURE 5: Design and assembly of 3D printed barnacle model.

barnacle, on the model surface, on two concentric circles of diameter $40 \mathrm{~mm}$ and $60 \mathrm{~mm}, 8$ tappings per ring equally distributed around the pitch circle. The orifices were $0.9 \mathrm{~mm}$ inner diameter brass inserts (Shaw, 1960) connected to a $\pm 7 \mathrm{kPa}$ range Scanivalve ZOC23B miniature pressure scanner by individual $1.5 \mathrm{~m}$ lengths of Saint-Gobain Tygon S3 flexible pressure tubing. Pressures were sampled at $125 \mathrm{~Hz}$ on a Scanivalve ERAD4000 Remote A/D, simultaneously with the principal experiments.

During oscillatory tests the model was first set to its mean angle of attack, and then allowed to run for five oscillatory cycles before pressure data were sampled for a further 10 consecutive cycles. Sampled data were low-pass filtered, each cycle was extracted from the waveform, data points were interpolated and a phase average computed to provide a time history of the dynamic pressure response. Pressure coefficients were integrated to calculate normal force, drag coefficient and pitching moment responses during the oscillatory pitching. Estimates of the section normal force, drag and moment coefficients in the vicinity of the barnacle were done by replacing the pressure transducer array data with the barnacle pressure tapping data in the affected area; the changes in the integrated coefficients are therefore not for the whole blade but represent the change to the local force or moment per unit span.

\subsection{Accuracy of methods and data analysis}

The absolute accuracy of the major items of instrumentation needs to be considered. The ZOC23B pressure scanner used for the barnacle pressure field measurement is able to resolve to better than $1 \mathrm{~Pa}$, and at the flow speeds (dynamic pressure) tested this is a pressure coefficient accuracy of better than $1 \%$. Each pressure transducer used for the main aerofoil pressure measurement array was calibrated, and based upon the data acquisition system performance the accuracy of the pressure transducer measurements was $\pm 10 \mathrm{~Pa}$, giving a pressure coefficient accuracy of around $1 \%$. The hydraulic motion system had a repeatability of angular positioning in static tests of better than $0.1^{\circ}$. Error on integrated loads due to relatively sparse spatial resolution of pressure measurement points was estimated using calculation of the pressure distribution using XFOIL and subsequent linear interpolation of pressure onto the pressure transducer locations. The differences in normal force, pressure drag and pitching moment coefficient were $0.1 \%, 8 \%$ and $0.5 \%$ respectively. For a wind tunnel test of an oscillating aerofoil the test start up transient has to be allowed to decay, and cycle-to-cycle repeatability is a well known issue in dynamic testing, therefore test data are presented as an average over a number of test cycles. An analysis of 50 consecutive oscillation cycles indicated that a load oscillation cycle became statistically stationary subject to a root-mean-square error of $1 \%$ relative to the average over 50 cycles after 10 cycles, so 10 test cycles were assessed as satisfactory.

The drag coefficient as presented is the integration of the pressure coefficient only. Skin friction coefficient was not measured. At low angle of attack in attached flow the contribution to the drag coefficient is predominantly from the skin friction, but contribution due to pressure becomes more significant at high angle of attack and is dominant in separated flow. A major feature of this investigation is the presence of the barnacle, and low angle of attack baseline 
drag measurements will be the least accurate. When compared to low angle of attack baseline flow, the drag analysis allows for a qualitative comparison of the effect of the barnacle.

\section{Results and discussion}

Data of the barnacle pressure distribution are presented for the static angle of attack and representative, unsteady cases. Effects on the blade section loading are then presented. The key parameter for the unsteady behaviour is the reduced frequency $k$, and analysis of field data obtained for tidal and wave motion indicate meaningful values of $k$ up to 0.1 for the outboard section of the tidal turbine where the current aerofoil section is designed. Representative mean angle of attack $\bar{\alpha}$ and amplitude $\hat{\alpha}$ are up to $10^{\circ}$ and $6^{\circ}$ respectively. Test Reynolds number was 1.5 million, and while this is below the field Reynolds number of 6 million for the tidal turbine, simulations of the aerofoil using XFOIL (Drela and Youngreen (2013)) indicate that the aerofoil loads are Reynolds number independent over this range. Individual barnacle pressure coefficients are cubically interpolated, in both radial and angular senses, and projected onto the blade $x z$-plane neglecting the local curvature of the aerofoil surface. The surface pressure coefficients are plotted in terms of the barnacle chordwise and spanwise position on the test section and centred on the barnacle central axis. The principal measurement array refers to the chordwise array of pressure transducers located around the blade mid-span, the barnacle measurement array refers to the pressure tappings on and around the barnacle model. The drag coefficient is calculated from pressure data only, the skin friction was not measured during the tests, and therefore the drag coefficient presented is the drag due to pressure only. This affects the fully attached flow result more significantly than the drag with separated flow.

\subsection{Steady Data for the Aerofoil and Barnacle Pressure Distribution}

The blade surface pressure distribution in the vicinity of the barnacle is of importance. Figure 6 shows blade surface pressure coefficient data in the region of the barnacle with and without the barnacle present. The barnacle data are across the barnacle centre-line. In each case the effect of the barnacle is highly localised, and the pressure data far ahead of and far behind the barnacle are indistinguishable from the barnacle-free case. In the immediate vicinity of the excrescence, however, there is significant deceleration in front of and suction behind the barnacle. This is less pronounced at the $\alpha=15^{\circ}$ case, where the pressure gradient in the barnacle-free case is low anyway and the aerofoil section is close to stall. Figure 7 presents the pressure contours around the barnacle at the same three static aerofoil angles of attack. The slight asymmetry in the pressure surface contours is a consequence of a pressure tapping on the barnacle upstream side being slightly recessed into the barnacle body. The pressure distributions at the two lower angles of attack show strong suction lobes to either side of the barnacle, and these would be consistent with the generation of a horse-shoe vortex by the ineraction of the blade surface boundary layer with the excrescence. This effect is only weak at the highest angle of attack, a result of the stall of the blade. Inspection of the measured pressure coefficients confirm that the pressure at the lateral extent of the barnacle measurement array, i.e. the outer tapping ring at a chordwise position of $x / c=0.6$, has recovered to the corresponding baseline pressure in the principal measurement array at the aerofoil midspan. This suggests that the lateral radial extent of the barnacle influence on the flow can be considered to be no greater than three times the base radius of the barnacle from the barnacle central axis, and a barnacle may be considered to be isolated from its neighbours from a hydrodynamic performance point of view at a lateral spacing of about 4 radii. The barnacle upstream influence on the flow will be of approximately the same distance, but the wake downstream of the barnacle will persist, at moderate angles of attack, significantly further. With increasing angle of attack the barnacle region of influence is decreased.

Aerofoil section normal force and drag coefficient data are shown in frames A and B of figure 8 , for which the principal measurement array pressure data were replaced with the barnacle data. The symbols are for every fifth angle of attack measured. For both the clean and barnacle cases the normal force increases at an almost uniform rate up until stall, when 
the normal force reaches a maximum and decreases as angle of attack continues to rise. The barnacle has no significant effect on the normal force. Drag coefficient for the baseline case is the lowest across the angle of attack range where the normal force behaviour shows attached flow, and the rapid increase in the drag coefficient at higher angle of attack is typical of any aerofoil. Drag coefficient at low angle of attack with the barnacle is much higher than for the baseline case, a difference much larger than can be attributed to any experimental error. The relative increase in the drag coefficient due to the barnacle is shown in frame $C$ of figure 8. Note that the data are somewhat noisy around $\alpha=0$, this is where the baseline $C_{d}$ is lowest, and a smoothed trend line is shown. However, the $\Delta C_{d}$ around low angle of attack is very high at around $800 \%$, while at higher positive and negative angles the change is smaller. The $\Delta C_{d}$ in stalled flow is negligible. Table 1 summarises the changes to the aerofoil behaviour in steady flow, where the normal force (and therefore lift) behaviour show negligible change due to the barnacle, but the change in minimum drag coefficient is very large indeed at around $800 \%$. This drag increase compared to the baseline case is likely to be much higher than it actually is, because the baseline drag coefficient presented in this paper does not include the skin friction component. Nevertheless the disruption to the blade surface boundary layer by the barnacle in fully attached flow will be very significant, and large drag increase would be expected.

TABLE 1: Summary of static aerofoil results with barnacle.

\begin{tabular}{cccc}
\hline Parameter & baseline & with barnacle & $\boldsymbol{\Delta}$ \\
\hline$C_{n_{\max }}$ & 1.23 & 1.23 & $0 \%$ \\
$\alpha_{\mathrm{ss}}\left[{ }^{\circ}\right]$ & 13.1 & 13.1 & 0 \\
$C_{n_{\alpha}}$ & 6.12 & 6.02 & $-2 \%$ \\
$\alpha_{C_{n}=0}\left[^{\circ}\right]$ & -3.6 & -3.6 & $0 \%$ \\
$C_{n_{\alpha=0}}$ & 0.4 & 0.39 & $-3 \%$ \\
\hline minimum $C_{d}$ & $\approx 0.003$ & $\approx 0.034$ & $\approx 800 \%$ from smoothed data \\
\hline
\end{tabular}

\subsection{Unsteady data}

Normal force and drag coefficient data for a sinusoidal motion profile with mean angle $\bar{\alpha}=10^{\circ}$, amplitude $\hat{\alpha}=5^{\circ}$, reduced frequency $k=0.1$ are shown in figure 9 . The aerodynamic coefficients form hysteresis loops that are typical of pitching aerofoil motion of this type, where there is a light dynamic stall. Normal force $C_{n}$, frame A, show similar behaviour with and without the barnacle. The lift curve slope remains at a high value on the upstroke, close to the fully attached steady flow value at low angle of attack, so that $C_{n}$ is higher than for the steady flow case (static) when separated flow would otherwise encroach in the steady flow case. The pitching motion changes direction at $\alpha=15^{\circ}$, flow separation begins to dominate the flow behaviour (light dynamic stall), and $C_{n}$ drops rapidly during the downstroke to below the static test value. Fully attached flow behaviour is regained rapidly as the angle of attack approaches the minimum value. Drag coefficient follows the steady flow (static) test data closely on the upstroke, drag coefficient remains higher on the downstroke due to the light dynamic stall, and the difference between drag on the upstroke and downstroke seems to be larger for the test case with the barnacle. Drag coefficient with the barnacle is less than the steady flow case for almost all of the upstroke phase. Effect of reduced frequency and mean angle on the drag coefficient is shown in figure 10; at low mean angle where the excursion into separated flow is small, the drag is close to the steady flow value, but at higher mean angle drag forms a hysteresis loop around the steady flow trend, and no other significant effect of reduced frequency is observed.

Pressure distributions around the barnacle for a sinusoidal motion profile with mean angle $\bar{\alpha}=10^{\circ}$, amplitude $\hat{\alpha}=5^{\circ}$, reduced frequency $k=0.1$ are shown in figure 11 . The contour plots may be compared with the steady flow case in figure 7. Slightly higher suction is observed on the upstroke compared to the steady flow case, while reduced suction is seen on the downstroke, and this is due to the dynamic stall and the continued presence of 
separated flow during the downstroke. In the pitching case at maximum angle $15^{\circ}$, there is still significant pressure change in the vicinity of the barnacle, while the steady test case shows only weak pressure changes around the barnacle. Fully attached flow behaviour has become fully established by the end of the downstroke at $\alpha=5^{\circ}$, and the steady flow and pitching pressure distributions are similar in appearance. At lower mean angles and lower reduced frequencies the differences of the barnacle pressure distributions between the steady flow (static angle of attack) and pitching cases is less significant; at lower mean angles the penetration into separated flow is less significant, and at lower reduced frequency the behaviour becomes quasi-steady.

\subsection{Effect of barnacle fouling on tidal turbine blade performance}

Degradation of blade section performance parameters can be used to estimate the change in the whole turbine performance using blade element momentum theory. Both momentum and blade element theories have been widely utilised and validated for the analysis of wind turbine performance, Manwell et al. (2002), and also that of horizontal-axis tidal stream turbines, Batten et al. (2007). This approach allows the turbine blade geometry parameters to be defined for a required performance under known flow conditions, or conversely, the turbine performance for known blade geometry and flow conditions. Additional model implementations relevant to tidal turbines are discussed in Masters et al. (2011). Details of the implementation of this method for the barnacle fouling described in this paper are described by Walker (2018). Data for the isolated barnacle can only be used to predict performance changes for a sparse barnacle encrustation. Furthermore a force balance method would need to be used to measure the changes due to a cluster of barnacles. It is not meaningful to predict the change of turbine performance due to barnacle encrustation alone, this is because barnacle infestation does not generally occur in the absence of any other fouling. The change to the blade section characteristics compared to the clean blade section characteristics are meaningful though, because they represent an easily definable problem as a first step in predicting overall fouling effect of for a basic understanding of the unsteady flow of a barnacle encrusted blade section. Sareen et al. (2014) show that for a wind turbine an annual energy production loss of $7 \%$ may occur as a result of an approximately $75 \%$ increase of blade drag. Turbine blade drag can be calculated from the blade section forces, and this can be done using the blade element theory by changing the local blade section performance characteristics according to whether that blade element contains a barnacle or not. Using steady flow data the blade drag $D$ is then

$$
D=\sum_{i=1}^{N} C_{d_{i}} q_{i} c_{i} \Delta r_{i} .
$$

The chord length $c_{i}$ variation is the blade shape, the dynamic pressure $q_{i}$ depends upon the tidal flow stream speed and the local blade element speed due to turbine rotation, and the element drag coefficient $C_{d_{i}}$ depends upon the blade section drag characteristics and the local angle of attack $\alpha$. Turbine blade section shape varies along the span from a thick section close to the root (for structural strength) to thinner sections outboard (typically 19\% thick). Calculations based upon meaningful flow conditions for an industrially relevant tidal turbine blade are described by Walker (2018), and a 75\% blade drag increase is observed with $50 \%$ of the blade elements affected by a barnacle. It is noted that the lift is not significantly affected.

\section{Conclusions}

The effect on the performance of a tidal turbine blade section due to a barnacle shaped excrescence on the surface has been investigated in steady and unsteady flow. Unsteady flow conditions are representative of those likely to be encountered by an operational tidal turbine. In steady flow the barnacle has no significant effect upon the lift, but there is a very large increase in the drag. While lift behaviour in unsteady flow can be very different to that during steady flow, the barnacle shaped excrescence has only limited effect on the lift behaviour during unsteady tests. Changes to the drag in unsteady flow are similar to those observed 


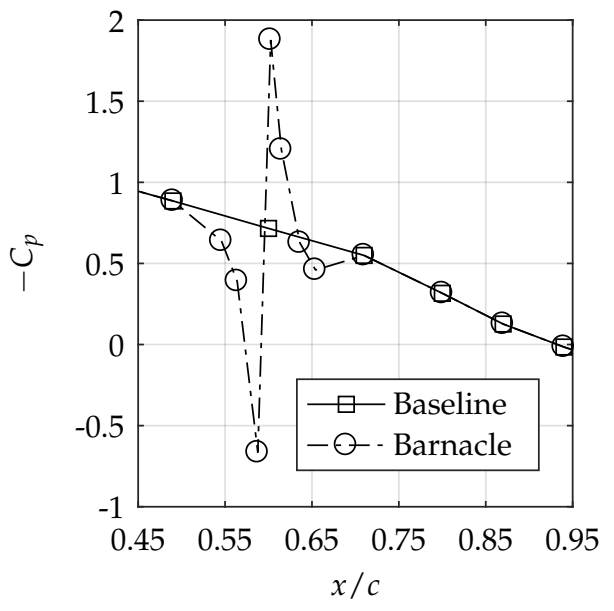

(A) $\alpha=5^{\circ}$

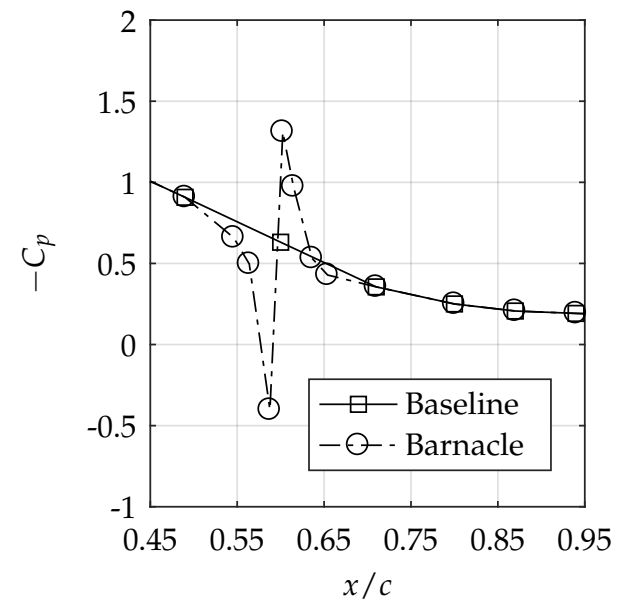

(в) $\alpha=10^{\circ}$

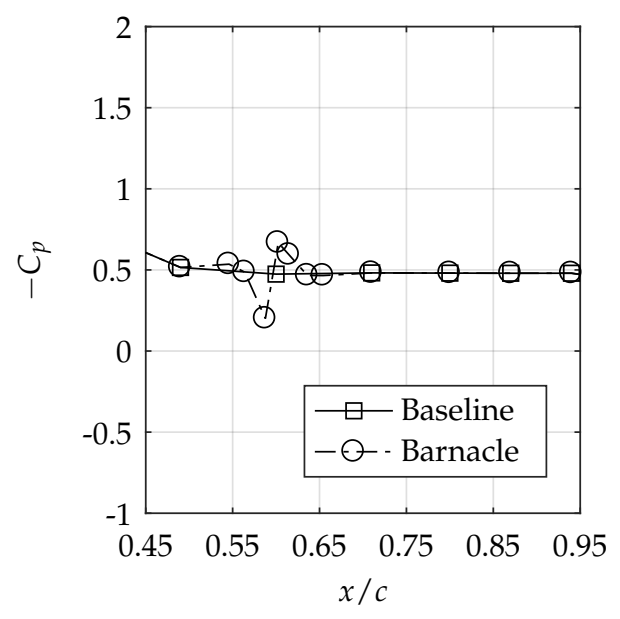

(c) $\alpha=15^{\circ}$

FIGURE 6: Static aerofoil surface chordwise pressure coefficients across the barnacle centre-line for selected angles.

during steady flow tests, although large hysteresis loops can be formed during the pitching cycle dependent upon the excursion into dynamic stall.

\section{Acknowledgements}

The experimental testing used resources provided by the EPSRC funded National Wind Tunnel Facility project, EP/L024888/1. 


\begin{tabular}{|c|c|c|c|c|c|c|c|}
\hline$-C_{p}$ & -0.5 & 0 & 0.5 & 1 & 1.5 & 2 & --- Barnacle Position \\
\hline
\end{tabular}

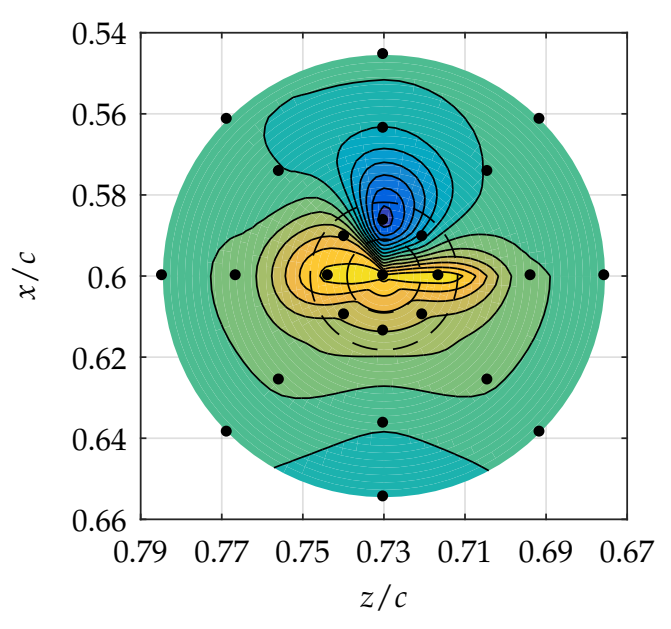

(A) $\alpha=5^{\circ}$

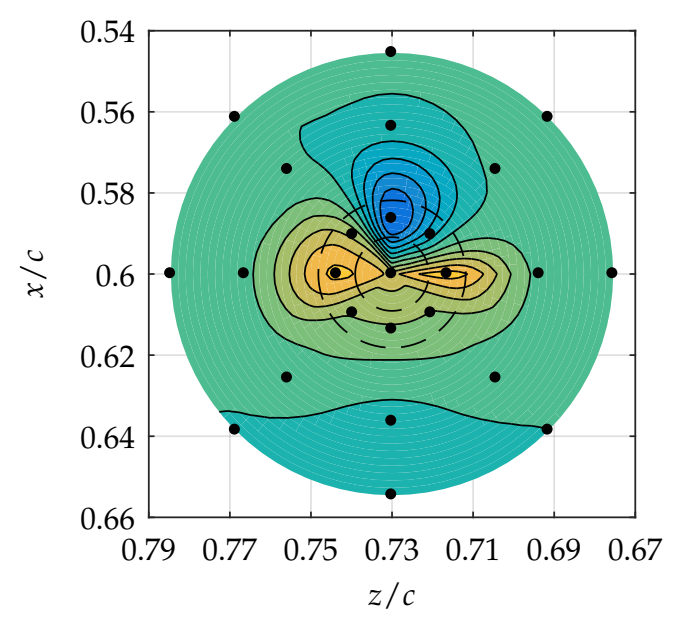

(в) $\alpha=10^{\circ}$

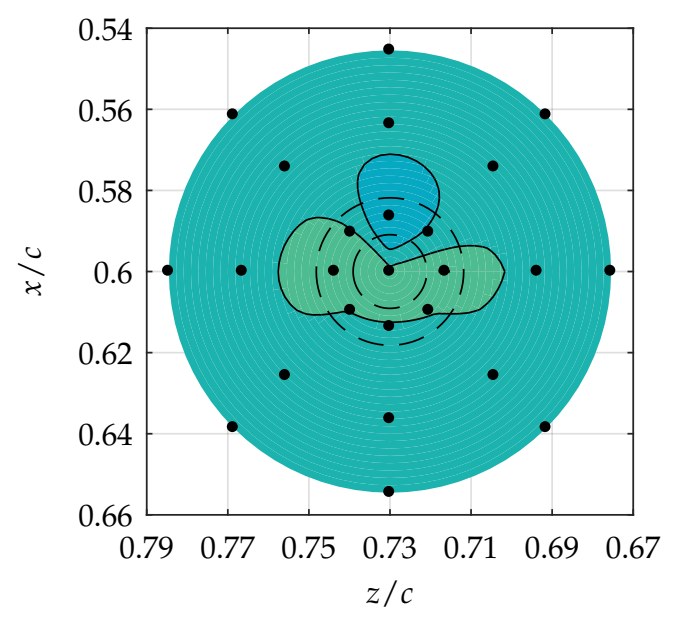

(c) $\alpha=15^{\circ}$

Figure 7: Pressure coefficient contours for steady flow around barnacle at selected static angles of attack. 


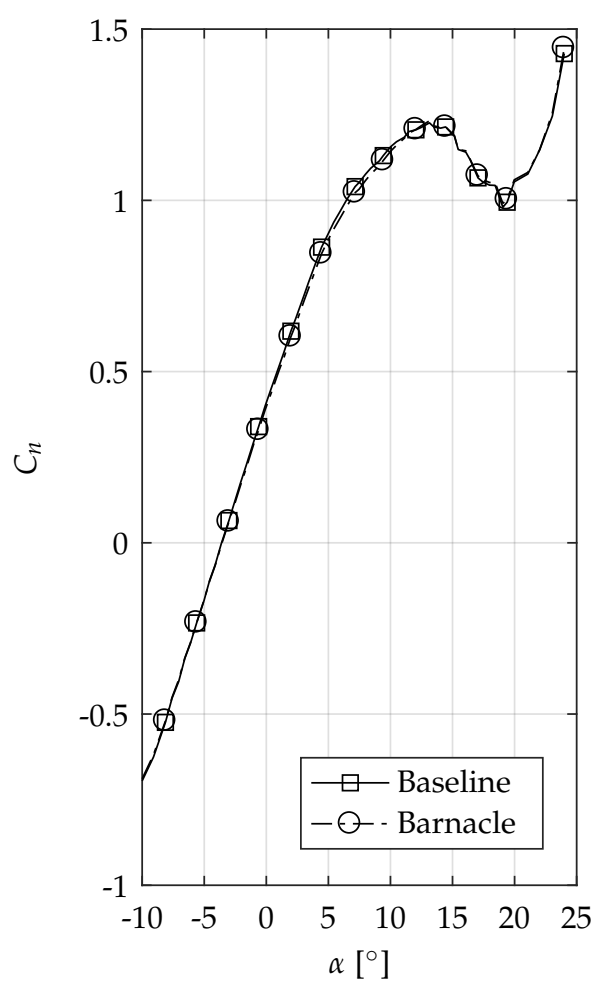

(A) Normal force coefficient

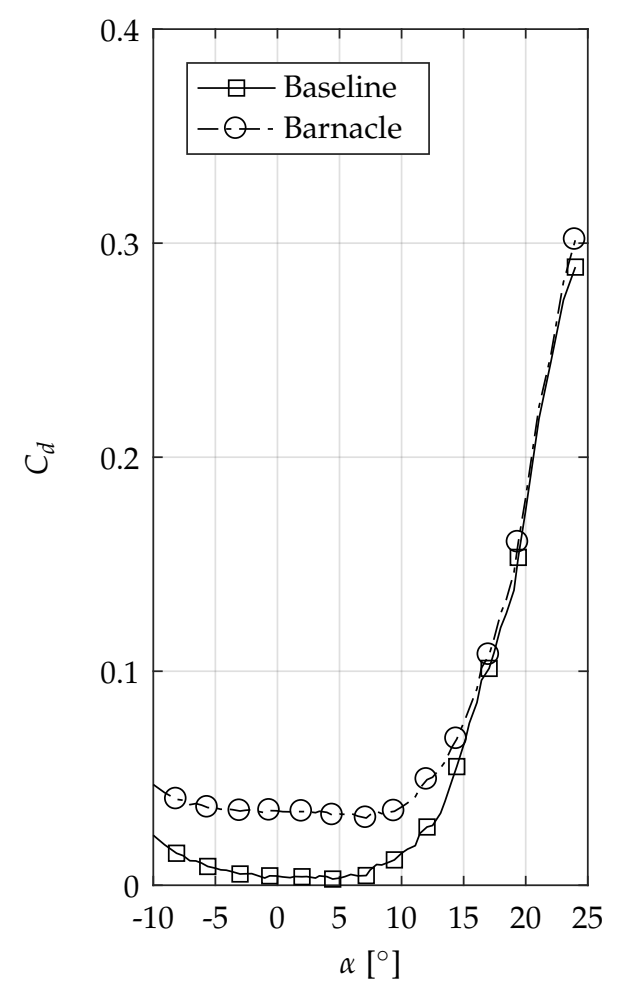

(в) Drag coefficient

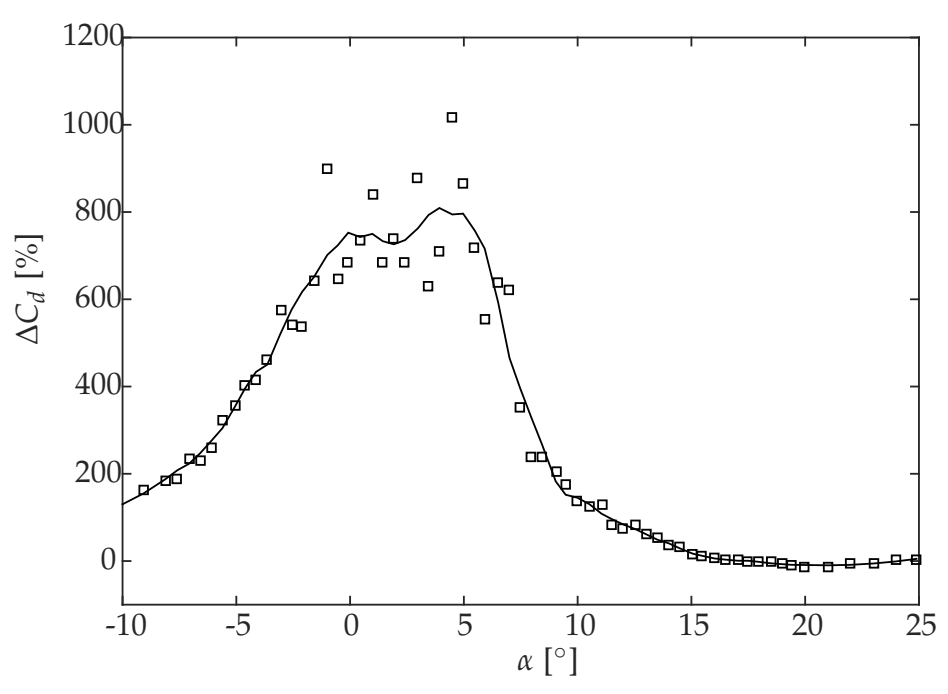

(c) Increase in drag coefficient, the solid line shows smoothed data.

FIGURE 8: Steady flow normal force and drag coefficient for baseline and barnacle datasets. 


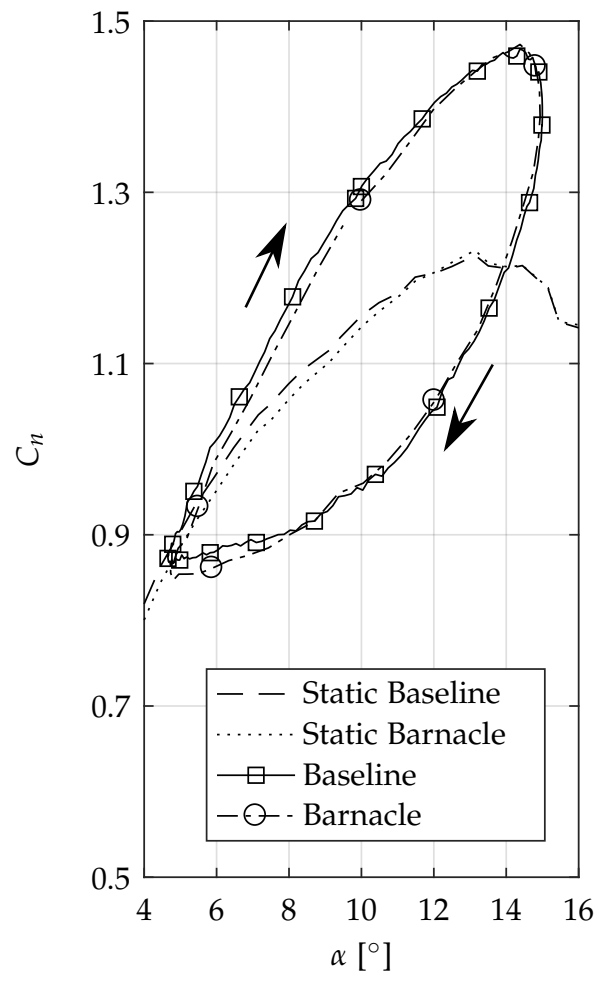

(A) Normal force coefficient

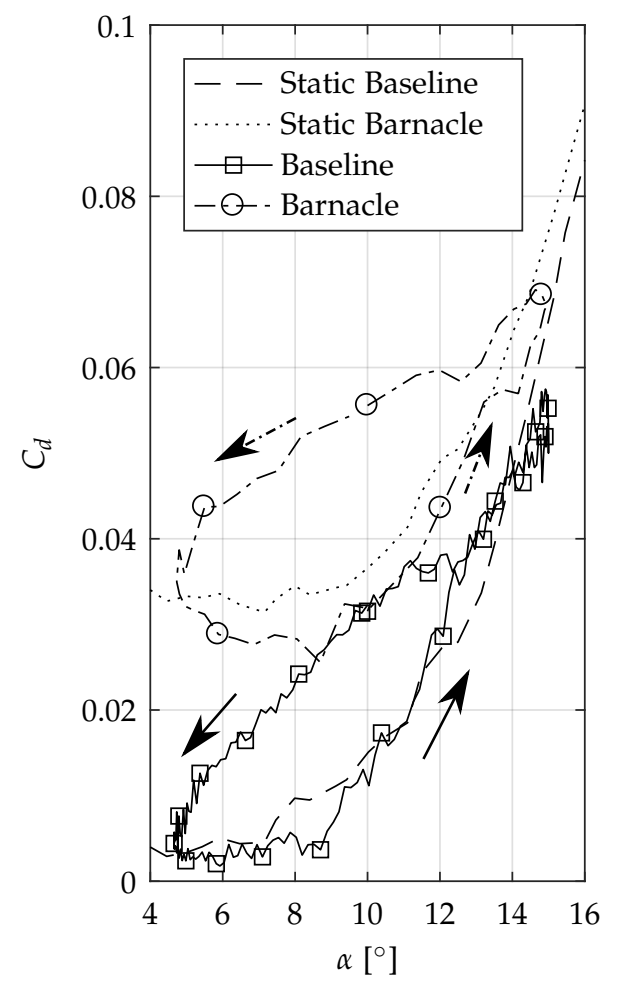

(в) Drag coefficient

FIGURE 9: Unsteady normal force and drag coefficient for baseline and barnacle datasets: $k=0.1, \alpha=10^{\circ} \pm 5^{\circ}$.

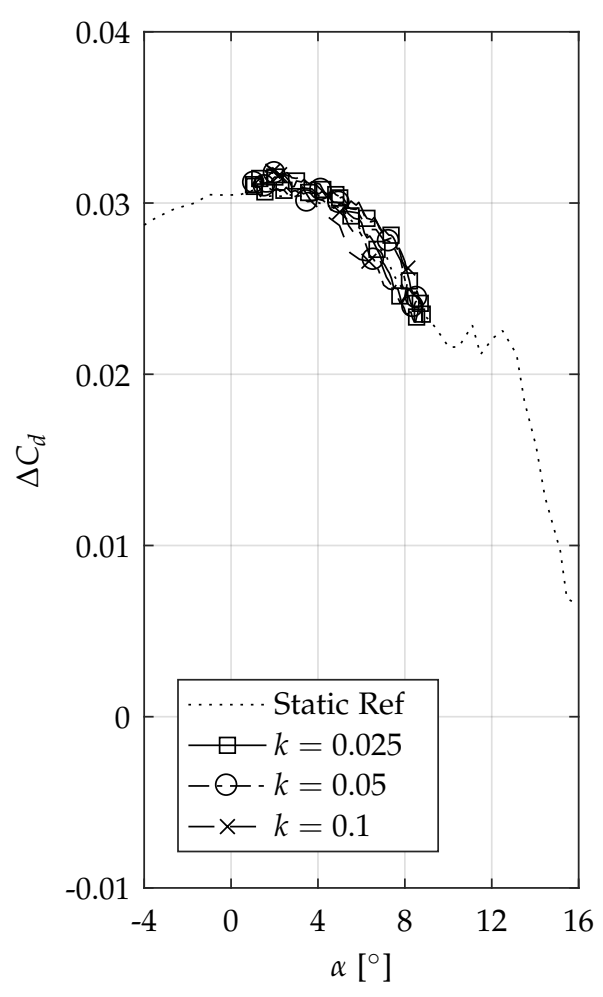

(A) $\alpha=5^{\circ} \pm 5^{\circ}$.

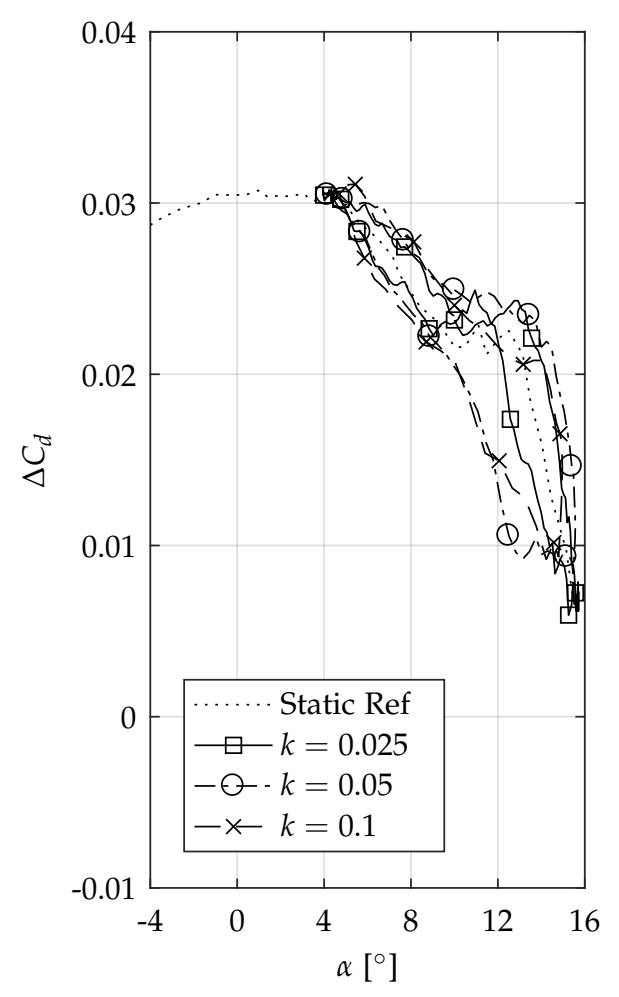

(в) $\alpha=10^{\circ} \pm 5^{\circ}$

FIGURE 10: Effect of varying reduced frequency on the pressure drag coefficient increment due to barnacle compared to clean aerofoil. 


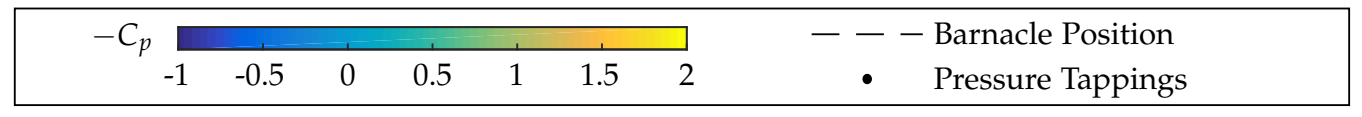

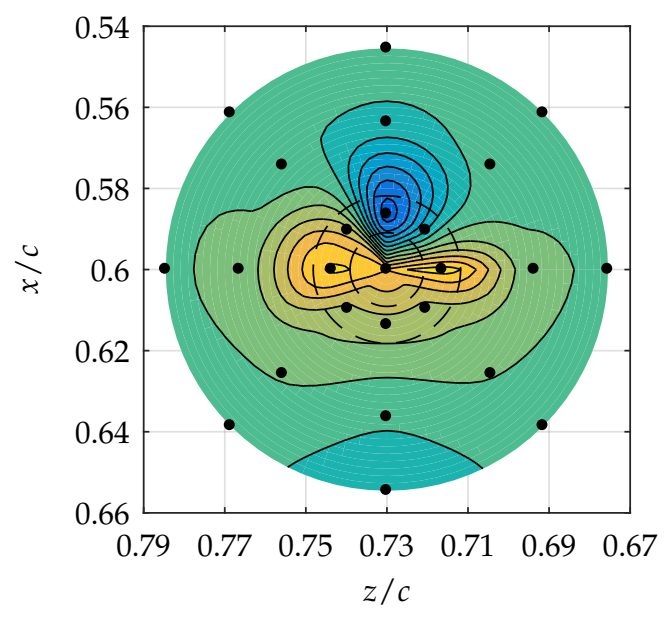

(A) Upstroke Motion: $10^{\circ}(\bar{\alpha})$

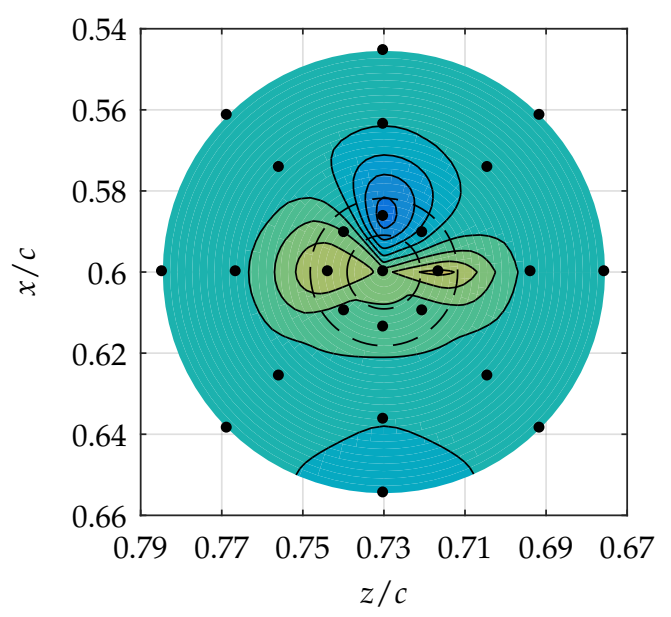

(c) Downstroke Motion: $10^{\circ}(\bar{\alpha})$

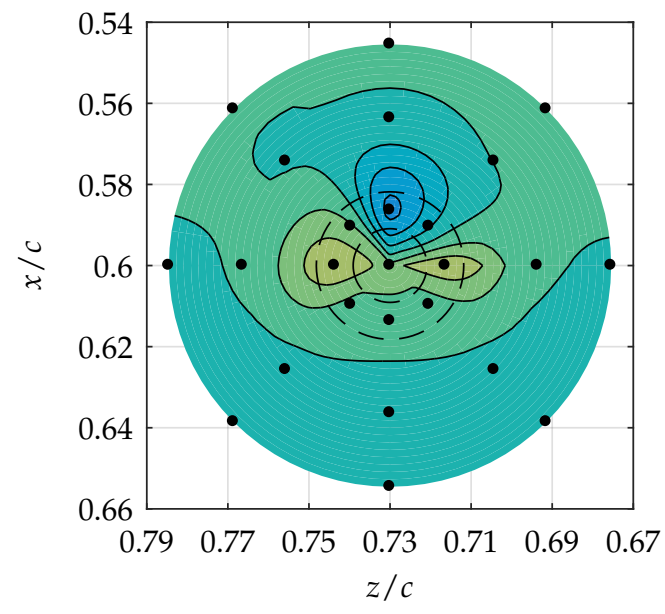

(в) Maximum Angle of Attack: $15^{\circ}$

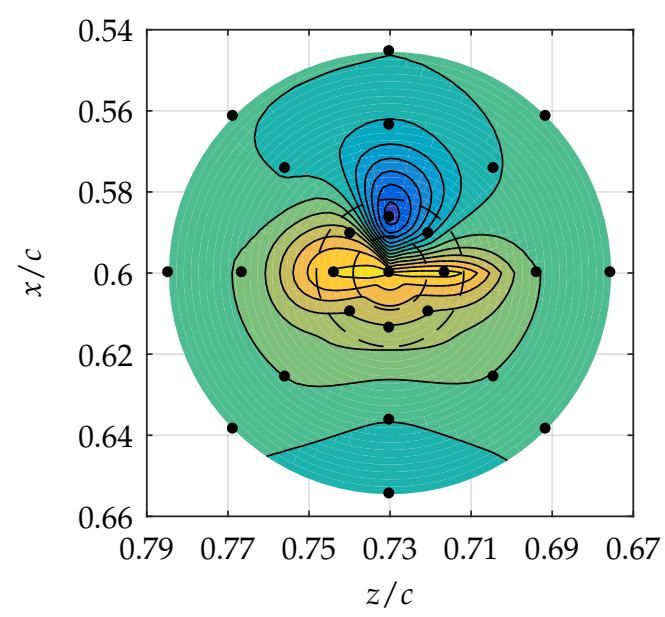

(D) Minimum Angle of Attack: $5^{\circ}$

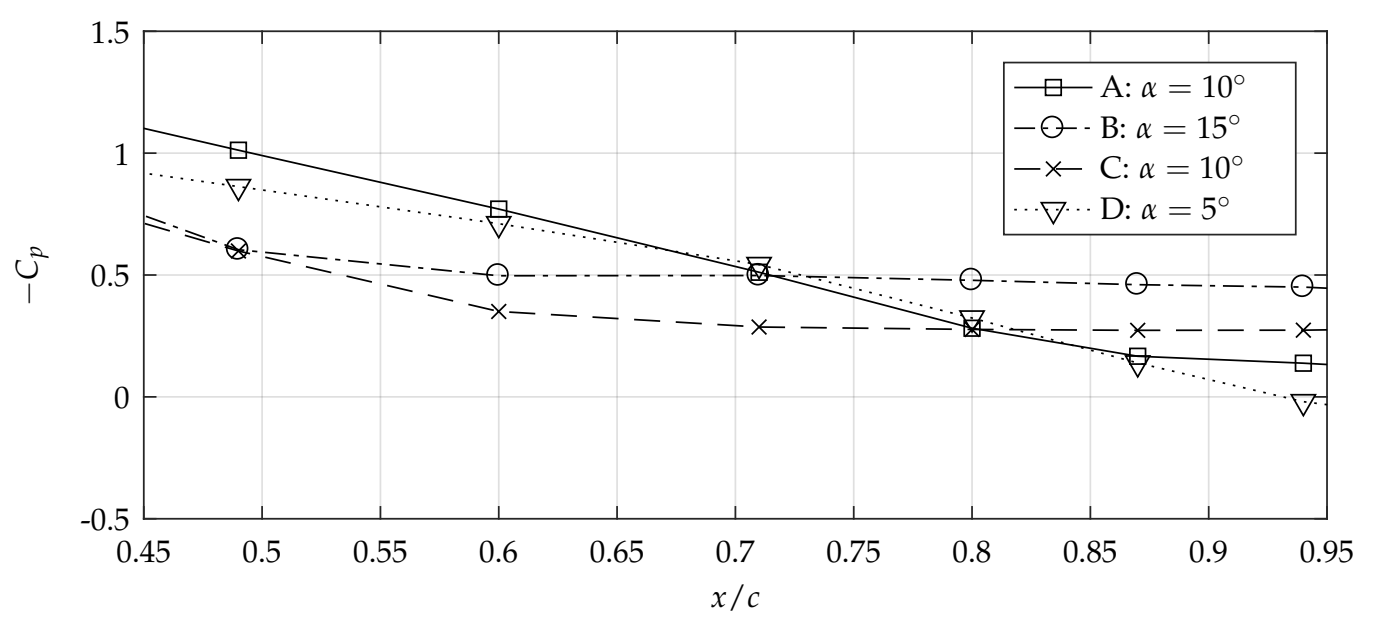

(E) Aerofoil Pressure Distribution (No Barnacle) for Subfigures A to D

Figure 11: Pressure coefficient contours around barnacle for oscillatory test in the clean configuration at selected angles of attack and reference chordwise pressure distribution: $k=0.1, \alpha=10^{\circ} \pm 5^{\circ}$. 


\section{References}

Alberto J Martín-Rodríguez, Jose MF Babarro, Fernando Lahoz, Marta Sansón, Víctor S Martín, Manuel Norte, and José J Fernández. From broad-spectrum biocides to quorum sensing disruptors and mussel repellents: Antifouling profile of alkyl triphenylphosphoniium salts. PLOS ONE, 10(4):e0123652, 2015.

Tom Vance, Robert Ellis, and Tim Fileman. Eti ma1001 - reliable data acquisition platform for tidal (redapt) project. Technical Report ME8.5 Final Report, Energy Technology Institute, Plymouth, UK, December 2014.

Michael F Kerho and Michael B Bragg. Airfoil boundary-layer development and transition with large leading edge roughness. AIAA Journal, 35(1):75-84, January 1997. doi: https: //doi.org/10.2514/2.65.

Itiro Tani. Boundary-layer transition. Annual Review of Fluid Mechanics, 1(1):169-196, January 1969. doi: https://doi.org/10.1146/annurev.fl.01.010169.001125.

FG Ergin and EB White. Unsteady and transitional flows behind roughness elements. AIAA Journal, 44(11):2504-2514, November 2006. doi: https://doi.org/10.2514/1.17459.

SK Roberts and MI Yaras. Boundary-layer transition affected by surface roughness and free-stream turbulence. Journal of Fluids Engineering, 127(3):449-457, May 2005. doi: https: //doi.org/10.1115/1.1906266.

PS Klebanoff, WG Cleveland, and KD Tidstrom. On the evolution of a turbulent boundary layer induced by a three-dimensional roughness element. Journal of Fluid Mechanics, 237: 101-187, April 1992. doi: doi:10.1017/S0022112092003379.

Eastman N Jacobs. Airfoil section characteristics as affected by protuberances. Technical Report 446, NACA, Washington (DC), USA, 1934.

MB Bragg, AP Broeren, and LA Blumenthal. Iced-airfoil aerodynamics. Progress in Aerospace Sciences, 41(5):323-362, July 2005. doi: https://doi.org/10.1016/j.paerosci.2005.07.001.

MJ Cummings and MB Bragg. Boundary-layer transition due to isolated three-dimensional roughness of airfoil leading edge. AIAA Journal, 34(9):1949-1952, September 1996. doi: https://doi.org/10.2514/3.13333.

H Johari, C Henoch, D Custodio, and A Levshin. Effects of leading-edge protuberances on airfoil performance. AIAA Journal, 45(11):2634-2642, November 2007. doi: https://doi.org/ 10.2514/1.28497.

A Theophanatos and J Wolfram. Hydrodynamic loading on macro-roughened cylinders of various aspect ratios. Journal of Offshore Mechanics and Arctic Engineering, 111(3):214-222, August 1989. doi: https://doi.org/10.1115/1.3257150.

MP Schultz, JA Bendick, ER Holm, and WM Hertel. Economic impact of biofouling on a naval surface ship. Biofouling, 27(1):87-98, January 2011. doi: https://doi.org/10.1080/08927014. 2010.542809 .

JAC Orme, I Masters, and RT Griffiths. Investigation of the effect of biofouling on the efficiency of marine current turbines. In Proceedings of MAREC2001, International Conference on Marine Renewable Energies, pages 91-99, London, UK, March 2001. Institute of Marine Engineers.

Markus Mueller and Robin Wallace. Enabling science and technology for marine renewable energy. Energy Policy, 36(12):4376-4382, December 2008. doi: https://doi.org/10.1016/j. enpol.2008.09.035.

KW Ng, WH Lam, and KC Ng. 2002-2012: 10 years of research progress in horizontal-axis marine current turbines. Energies, 6(3):1497-1526, March 2013. doi: https://doi.org/10.3390/ en6031497. 
YS Khor and Q Xiao. Cfd simulations of the effects of fouling and antifouling. Ocean Engineering, 38(10):1065-1079, July 2011. doi: https://doi.org/10.1016/j.oceaneng.2011.03. 004.

EMEC. Andritz hydro hammerfest: Emec: European marine energy centre, February 2017. URL http://www.emec.org.uk/about-us/our-tidal-clients/andritz-hydro-hammerfest/. Accessed: $22^{\text {nd }}$ February 2017.

Y.K. Demirel, D. Uzun, Y. Zhang, H.-C. Fang, A.H. Day, and O. Turan. Effect of barnacle fouling on ship resistance and powering. Biofouling, 33:819-834, October 2017. doi: https: / / doi.org/10.1080/08927014.2017.1373279.

S. Song, Y. K. Demirel, and M. Atlar. Penalty of hull and propeller fouling on ship selfpropulsion performance. Applied Ocean Research, 94(102006):1-24, January 2020a. doi: https://doi.org/10.1016/j.apor.2019.102006.

S. Song, , W. Shi, Y. K. Demirel, and M. Atlar. The effect of biofouling on the tidal turbine performance. In Applied Energy Symposium: MIT A+B, Massachusetts Institute of Technology, Boston (MA), USA, 2019.

S. Song, Y. K. Demirel, M. Atlar, and W. Shi. Prediction of the fouling penalty on the tidal turbine performance and development of its mitigation measures. Applied Energy, 276 (115498), October 2020b. doi: https://doi.org/10.1016/j.apenergy.2020.115498.

A J Southward. Barnacles: Keys and Notes for the Identification of British Species. Field Studies Council, February 2008.

H Barnes and HT Powell. The growth of Balanus Balanoides (1.) and B. Crenatus brug. under varying conditions of submersion. Journal of the Marine Biological Association of the United Kingdom, 32(1):107-127, June 1953.

Jasim Sadique, Xiang IA Yang, Charles Meneveau, and Rajat Mittal. Simulation of boundary layer flows over biofouled surfaces. Paper presented at AIAA 22nd Computational Fluid Dynamics Conference, Dallas, TX, June 2015.

$\mathrm{R}$ Shaw. The influence of hole dimensions on static pressure measurements. Journal of Fluid Mechanics, 7(4):550-564, April 1960. doi: doi:10.1017/S0022112060000281.

Mark Drela and Harold Youngreen. Xfoil 6.99, December 2013. URL http://web.mit.edu/ drela/Public/web/xfoil/. Accessed: 10 $0^{\text {th }}$ October 2016.

James F Manwell, Jon G McGowan, and Anthony L Rogers. Wind Energy Explained: Theory, Design and Application. Wiley, June 2002.

WMJ Batten, AS Bahaj, AF Molland, and JR Chaplin. Experimentally validated numerical method for the hydrodynamic design of horizontal axis tidal turbine. Ocean Engineering, 34 (7):1013-1020, May 2007. doi: https://doi.org/10.1016/j.oceaneng.2006.04.008.

I Masters, JC Chapman, and MR Willis. A robust blade element momentum theory model for tidal stream turbines including tip and hub loss corrections. Journal of Marine Engineering and Technology, 10(1):25-35, January 2011. doi: https://doi.org/10.1080/20464177.2011.11020241.

John Scott Walker. Dynamic loading and stall of clean and fouled tidal turbine blade sections, January 2018. PhD dissertation, University of Glasgow, Glasgow, Scotland.

Agrim Sareen, Chinmay A Sapre, and Michael S Selig. Effects of leading edge erosion on wind turbine blade performance. Wind Energy, 17(10):1531-1542, October 2014. doi: https://doi.org/10.1002/we.1649. 